\title{
STAR VaS - Short Term Atorvastatin Regime for Vasculopathic Subjects: a randomized placebo-controlled trial evaluating perioperative atorvastatin therapy in noncardiac surgery STAR VaS - Traitement de courte durée à l'atorvastatine chez des patients souffrant de vasculopathie: étude randomisée contre placebo évaluant un traitement périopératoire à l'atorvastatine en chirurgie non cardiaque
}

\author{
David T. Neilipovitz, MD • Gregory L. Bryson, MD • \\ Monica Taljaard, PhD
}

Received: 14 November 2011 / Accepted: 19 March 2012/Published online: 13 April 2012

(C) Canadian Anesthesiologists' Society 2012

\begin{abstract}
Purpose Evidence suggests that statins reduce cardiovascular complications in patients undergoing noncardiac surgery, although questions remain regarding the mechanism of benefit and the preferred dosing strategy. In this trial, we evaluated the perioperative effects on $C$-reactive protein (CRP) that resulted from starting atorvastatin within seven days of noncardiac surgery. The objective was to identify anti-inflammatory effects of atorvastatin prior to conducting a large randomized trial with clinical end points.
\end{abstract}

This article is accompanied by two editorials. Please see Can J Anesth 2012; 59(6).

Author contributions David T. Neilipovitz was the primary investigator and author. David T. Neilipovitz and Gregory L. Bryson helped conduct the study. David T. Neilipovitz, Gregory L. Bryson, and Monica Taljaard helped design the study, analyze the data, write the manuscript, and secure funding. They have seen the original study data and reviewed the analysis of the data.

D. T. Neilipovitz, MD ( $\bowtie)$

Department of Critical Care Medicine, The Ottawa Hospital, University of Ottawa, Civic Campus, Room F202a, 1053 Carling Avenue, Box 249C, Ottawa, ON K1Y 4E9, Canada

e-mail: dneilipovitz@toh.on.ca

D. T. Neilipovitz, MD · G. L. Bryson, MD

Department of Anesthesiology, The Ottawa Hospital, University of Ottawa, Ottawa, ON, Canada

M. Taljaard, $\mathrm{PhD}$

Ottawa Hospital Research Institute, Ottawa, ON, Canada
Methods In a single centre, parallel group, placebocontrolled trial, sixty high cardiac risk participants over age 45 yr undergoing noncardiac surgery were assigned randomly to one of three groups to receive atorvastatin $80 \mathrm{mg}(A)$ and/or placebo $(P)$. Group $A A \quad(n=26)$ received atorvastatin seven days before surgery, the day of surgery, and for seven days post surgery. Group PA $(n=17)$ received placebo seven days before surgery, atorvastatin on the day of surgery, and atorvastatin for seven days post surgery. Group PP $(n=17)$ received placebo at all times. All participants, health care professionals, research assistants, and outcome adjudicators were masked to treatment allocation. Analyses were by intention to treat. The primary outcome was the $C$-reactive protein level at $48 \mathrm{hr}$.

Results Fifty-six participants completed the 30-day follow-up. The mean (standard deviation) changes in CRP levels from baseline at $48 \mathrm{hr}$ in Groups $A A, P A$, and $P P$ were 141.0 (72.4), 153.5 (42.2), and 111.2 (84.6), respectively. The mean differences (95\% confidence interval) at $48 \mathrm{hr}$ for $A A$ vs $P A, A A$ vs $P P$, and $P A$ vs $P P$ were: -20.1 (-81.2 to 41.1$), 22.7$ (-31.7 to 77.2$)$, and $42.8(-20.0$ to 105.7), respectively, adjusting for baseline CRP, type of procedure, presence of coronary artery disease, use of medications, and for multiple comparisons using Tukey's method.

Conclusions Administration of atorvastatin, initiated within seven days preoperatively, was not associated with clinically significant reductions in CRP levels. (ClinicalTrials.gov number, NCT00967434). 


\section{Résumé}

Objectif Des données probantes suggèrent que les statines réduisent les complications cardiovasculaires chez des patients subissant une chirurgie non cardiaque bien que des questions demeurent concernant le mécanisme de ce bénéfice et la meilleure stratégie posologique à adopter. Au cours de cette étude, nous avons évalué les effets périopératoires sur la protéine $C$-réactive (CRP) résultant d'une prise d'atorvastatine commençant dans les sept jours précédant une chirurgie non cardiaque. L'objectif était d'identifier les effets anti-inflammatoires de l'atorvastatine avant de mener une grande étude randomisée comportant des critères cliniques d'évaluation.

Méthodes Soixante participants d'un seul centre, à risque cardiaque élevé, âgés de plus de 45 ans et devant subir une chirurgie non cardiaque, ont participé à une étude randomisée contre placebo et à groupes parallèles; ils ont étérandomisés dans l'un des trois groupes pour y recevoir de l'atorvastatine $80 \mathrm{mg}(A)$ et/ou un placebo $(P)$. Les patients du groupe $A A(n=26)$ ont reçu de l'atorvastatine pendant sept jours avant la chirurgie, le jour de la chirurgie, et pendant sept jours après l'intervention chirurgicale. Les patients du groupe PA $(n=17)$ ont reçu un placebo pendant sept jours avant la chirurgie, de l'atorvastatine le jour de la chirurgie et pendant sept jours après l'intervention chirurgicale. Les patients du groupe PP $(n=17)$ ont reçu un placebo pendant toute la durée de l'étude. Tous les participants (professionnels de soins de santé, assistants de recherche et évaluateurs des résultats) ignoraient l'assignation au groupe de traitement. Les analyses ont été réalisées sur l'intention de traiter. Le principal critère d'évaluation était le taux de protéine C-réactive à 48 heures. Résultats Cinquante-six participants ont terminé le suivi de 30 jours. Les variations moyennes (écart-type) des concentrations de CRP à 48 heures par rapport à la ligne de base dans les groupes AA, PA et PP ont été, respectivement, de 141,0 (72,4), 153,5 (42,2) et de 111,2 $(84,6)$. Les différences moyennes (intervalle de confiance à $95 \%)$ à 48 heures pour les groupes AA contre PA, AA contre PP et PA contre PP ont été, respectivement: $-20,1$ $(-81,2$ à 41,1), 22,7 (-31,7 à77,2), et 42,8 (-20,0 à 105,7), après ajustement pour la CRP à la ligne de base, le type d'intervention, la présence d'une coronaropathie, l'utilisation de médicaments et pour les comparaisons multiples selon la méthode de Tukey.

Conclusions L'administration d'atorvastatine, débutée dans les sept jours précédant une intervention chirurgicale n'a pas été associée à des baisses cliniquement significatives des concentrations de CRP. (Numéro ClinicalTrials.gov: NCT00967434).
Despite advances in perioperative care, patients undergoing surgery remain at risk for cardiovascular complications leading to morbidity and mortality. ${ }^{1,2}$ An estimated two million North Americans experience a perioperative cardiac event with an estimated cost of more than twenty billion dollars annually. ${ }^{1,2}$ Traditional descriptions of perioperative myocardial infarction assumed an imbalance of myocardial oxygen supply and demand resulting from hypotension or hypoxia. Evidence, however, suggests that coronary artery thrombosis is as important a mechanism in perioperative myocardial infarctions as it is in nonoperative cardiac events. ${ }^{3-8}$ Inflammation may have a crucial role in coronary thrombosis as elevated levels of various inflammatory markers, particularly C-reactive protein (CRP), are associated with an increased probability of adverse cardiovascular events. ${ }^{9}$ As the inflammatory changes in nonoperative cardiac events are indistinguishable from the inflammatory changes that occur post surgery, it is possible that inflammation contributes to perioperative cardiac complications. ${ }^{9}$ Failure to address inflammation may explain the equivocal results of trials whose interventions focus on supply-demand relationships, such as perioperative beta-blockers. ${ }^{10}$

The 3-hydroxy-3-methylglutaryl-coenzyme A reductase inhibitors (henceforth called statins), are used traditionally to improve lipid profiles in patients with hypercholesterolemia. The benefits of statins, as evidenced by their pleiotropic effects, ${ }^{1,11}$ go well beyond improving lipid levels. Pleiotropic effects include anti-inflammatory properties, endothelial function changes, and cardiac artery plaque stabilization. ${ }^{1,11}$ Evidence suggests statins may also reduce perioperative cardiac complications. ${ }^{12-15}$ The European Society of Cardiology now endorses use of perioperative statins as a Type $1 \mathrm{~b}$ recommendation for patients at increased perioperative cardiac risk provided the drugs are started a minimum of one week before surgery. ${ }^{16}$ For many patients undergoing surgery, a week or more of preoperative preparation is not feasible. It remains unclear if the short-term (seven days or less) or acute (day of surgery) administration of a statin in preparation for urgent surgery would have a similar benefit.

Before committing to a large multicentre trial evaluating major adverse cardiac events, we aimed to establish if a statin's postoperative effect on inflammation would occur with up to a week of preoperative statin use. The study was designed specifically to assess the anti-inflammatory effect and safety of short-term use of atorvastatin in statin-naïve patients at high cardiac risk undergoing noncardiac surgery. Our primary hypothesis was that anti-inflammatory benefits of perioperative statin drugs, as assessed by CRP, would be apparent within $48 \mathrm{hr}$ after surgery. 


\section{Methods}

\section{Study design}

The reporting of this randomized, double-blind, placebocontrolled trial follows the CONSORT 2010 statement. ${ }^{16}$ Following Ottawa Hospital Research Ethics Board approval (Protocol \# 2006832) patients undergoing noncardiac surgery at the Ottawa Hospital, a 1,000 bed academic tertiary care centre, were assessed for eligibility. Eligibility criteria were patients who were aged $\geq 45 \mathrm{yr}$, those not taking a statin, and those considered at moderate to high risk for perioperative coronary events. The latter were defined using the inclusion criteria of the POISE trial, ${ }^{10}$ namely, patients with a history of coronary artery disease, peripheral vascular disease, stroke, or congestive heart failure, or three of six risk factors (details in Appendix 1). Exclusion criteria included patients who did not provide consent and those who had a contraindication to a statin (i.e., liver insufficiency or cirrhosis, active muscular disorder or myopathy, or previous adverse reaction to any statin), were pregnant, were enrolled in another study, or were previously enrolled in the Short Term Atorvastatin Regime for Vasculopathic Subjects (STAR VaS) trial. Patients with chronic atrial fibrillation or other conduction delays (e.g., left bundle branch block) that impair Holter monitoring interpretation remained eligible for the trial but did not participate in Holter analysis.

Research assistants approached potential participants in surgery, anesthesia, and cardiology clinics. After obtaining written informed consent, participants were assigned a unique trial number and were randomly allocated to one of three study groups: Group AA received atorvastatin $80 \mathrm{mg}$ once daily for seven days preoperatively, on the day of surgery, and for seven days after surgery. Group PA received placebo up to seven days preoperatively, and atorvastatin $80 \mathrm{mg}$ once daily on the day of surgery and for seven days postoperatively. Group PP received placebo at all intervals. Participants were assigned to treatment groups using a computer generated random numbers table created by an investigator not involved with bedside care or outcome assessment. Randomization was blocked in groups of six and stratified by procedure (aortic aneurysm, infrainguinal revascularization, or nonvascular surgery). The randomization schedule was held in the Ottawa Hospital Pharmacy. A pharmacist who was not involved with the study prepared and dispensed all study medications as identical capsules in similar sequentially numbered containers. Participants, care providers, investigators, and research personnel remained blinded to intervention throughout the study. The timing of all investigations is outlined in Fig. 1 and Appendix 2. Fasting before blood samples was not required, but samples were usually drawn with the early morning blood work before most patients have been served breakfast.

Despite full cooperation from all surgical services, many patients could not be approached for study participation more than seven days before surgery. To enhance recruitment, we obtained approval for a protocol amendment modifying enrolment criteria. The amendment permitted those patients presenting less than seven days before surgery to be entered into the short randomization arm (Fig. 1) of the study, and therefore, they could be assigned only to Group PA or to Group PP. The short randomization patients were randomized equally to either Group PA or Group PP.

It was assumed that more patients would present in the short randomization period (under seven days until surgery) than in the long randomization period (seven or more days before surgery). Therefore, to avoid underrepresentation in Group AA, patients presenting more than seven days before surgery were randomized disproportionately to Group AA using a ratio of 4:1:1 (Group AA, Group PA, Group PP, respectively). All participants in the individual groupings received the identical study drug two to four hours prior to surgery and once daily on postoperative days one through seven. Anesthesia, surgery, and postoperative care were not standardized in the study design and were performed at the discretion of the health care team.

\section{Outcome measures}

A schedule of study measures is provided in Appendix 2. The primary outcome was CRP at $48 \mathrm{hr}$ postoperatively (CardioPhase ${ }^{\circledR}$ high sensitivity CRP, Siemens, NY, USA) as C-reactive protein typically increases after surgery and peaks at $48 \mathrm{hr}^{12,13}$ A $33 \%$ relative difference would be consistent with a clinically relevant anti-inflammatory effect, and it is a magnitude associated with reduced cardiac events in non-surgical populations. ${ }^{17}$ Secondary outcomes included serum lipids to document atorvastatin absorption and non-inflammatory efficacy as well as creatine kinase and liver transaminases to assess atorvastatin safety. To address measurements required of a definitive trial with clinical outcomes, we documented the occurrence of the following events within seven days of surgery: myocardial ischemia, myocardial infarction and cardiac arrest, new onset cardiac arrhythmia, cerebral vascular accident, and death from all causes. Myocardial complications were adopted from the POISE study. ${ }^{10}$ Myocardial ischemia was defined as a reversible ST segment shift of $\geq 0.1 \mathrm{mV}$ depression at J-point $+60 \mathrm{msec}$ or as $\mathrm{a} \geq 0.2 \mathrm{mV}$ increase at J-point for one minute or more that was detected within the first $48 \mathrm{hr}$ postoperatively by continuous electrocardiogram (ECG) and/or Holter monitoring. Myocardial infarction was predefined either as 
Fig. 1 Study flow CONSORT diagram. CONSORT diagram and description of when study drug and investigations were conducted

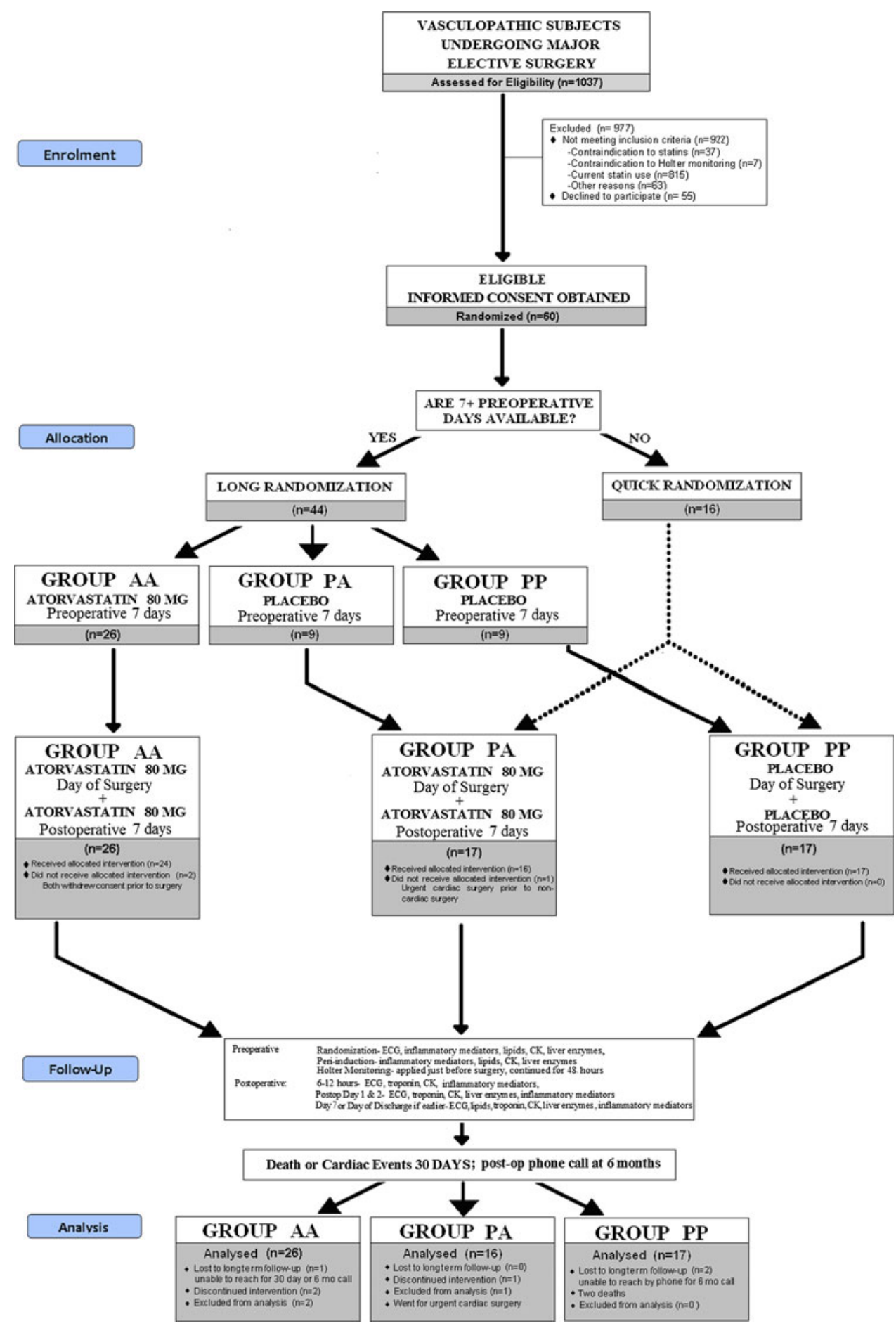

pathologic tissue findings or as a troponin increase above the 99th percentile and one of the following: 1) ECG changes; 2) coronary artery intervention; 3) echocardiography changes suggesting a new regional wall motion abnormality; or 4) clinical correlation. Duration of hospitalization was also recorded. Participants or their representative were contacted by telephone on day 30 and day 180 to determine the occurrence of medical complications or death.
Statistical analysis

The study was designed to detect a $33 \%$ relative difference in CRP between either treatment group vs placebo at $48 \mathrm{hr}$ postoperatively. Assuming a mean CRP level of $100 \mathrm{mg} \cdot \mathrm{L}^{-1}$ at $48 \mathrm{hr}$ in the placebo group, a common standard deviation of 33, and a type 1 error rate of 0.05 (two-sided), 17 patients per group would be required to detect the desired difference with $80 \%$ power (Hintze J, 2004; NCSS and PASS Number 
Cruncher Statistical Systems, UT, USA, www.NCSS.com). We based the sample size on a single two-sample Student's $t$ test, and no adjustment was made for the three pairwise between-group comparisons of interest. Sample size was increased to twenty patients per group $(n=60)$ to account for withdrawals and incomplete assessments.

Descriptive statistics (mean and standard deviation, or median and interquartile range for skewed distributions, or frequencies and proportions) were used to describe baseline demographic and clinical characteristics among the groups. C-reactive protein measures at $48 \mathrm{hr}$ were analyzed by analysis of covariance (ANCOVA) incorporating baseline $\mathrm{CRP}$ and the stratification factor (procedure) as covariates. Least square mean differences were calculated, and pairwise differences between groups were estimated with $95 \%$ confidence intervals, adjusted for multiplicity using Tukey's method. A second regression analysis was also performed adjusting for potential confounders (coronary artery disease and medication use: acetylsalicylic acid, cyclooxygenase inhibitors (COX)-2 inhibitors, or non-steroidal anti-inflammatory drugs [NSAIDs]). All analyses were carried out using SAS $^{\circledR}$ version 9.2 (SAS Institute Inc., Cary, NC, USA).

\section{Results}

\section{Patients}

From February 2008 to March 2010, 1,037 patients were screened to identify 115 eligible patients for the study. Patient flow through the study, including reasons for exclusion and withdrawal, are summarized in Fig. 1. Sixty participants provided informed written consent and were enrolled into the study: 26 patients were randomized to Group AA, and 17 patients were randomized to each of Groups PA and PP. Two participants in Group AA withdrew study consent after randomization but before their date of surgery. The first participant's surgery was cancelled because of hospital bed shortages and the participant subsequently withdrew consent. The second participant withdrew consent because of an inability to swallow the study pills because of an esophageal stricture. One patient underwent urgent cardiac surgery after allocation to Group PA but before undergoing the index noncardiac procedure. One participant in Group PP could not be contacted for the 30-day follow-up. The remaining 56 participants completed the 30-day follow-up. Patient characteristics and indicators of disease severity within the three groups are listed in Table 1.

Primary outcome

Boxplots showing the observed distribution for CRP over time are presented in Fig. 2. There was large variability in postoperative CRP levels among the groups. C-reactive protein levels increased in all groups following surgery. The highest levels were reached at $48 \mathrm{hr}$, and levels declined by postoperative day seven. Observed mean (and median) CRP levels were lower in Group PP at all postoperative measurement times.

The results from the ANCOVA and regression analyses of CRP are presented in Table 2. The observed mean CRP values drawn at baseline and on postoperative day two are presented as well as the change from baseline to postoperative day two. Contrary to expectations, observed and adjusted mean CRP levels were higher in the treatment groups vs placebo. Adjusted means for pairwise differences between the groups are presented together with the $95 \%$ confidence intervals. The adjusted pairwise confidence intervals excluded the hypothesized $33 \%$ relative reductions in mean CRP levels at $48 \mathrm{hr}$; thus, there was insufficient evidence to conclude that atorvastatin $80 \mathrm{mg}$ given to participants in Groups AA and PA meaningfully reduced the anticipated postoperative increase in CRP. Adjustment for potential confounders (presence of coronary artery disease and use of acetylsalicylic acid, COX-2 inhibitors, or NSAIDS) did not have a substantial impact on the mean differences or confidence intervals.

\section{Secondary outcomes}

There were no perioperative deaths, cardiac arrests, or cerebral vascular accidents. Holter monitoring was conducted and interpretable in 51 of 59 patients. Holter monitoring was not performed in eight patients due to chronic atrial fibrillation (six) or withdrawal from the study (two). For each of the myocardial complications, the proportion of patients suffering an incident was similar in the three groups (Table 3). A new cardiac arrhythmia occurred in $39 \%$ of patients with atrial arrhythmias being the most frequent rhythm disturbance.

Boxplots showing the observed distributions for lipids over time are presented in Fig. 3. Observed distributions for lipids were similar at baseline, but they differed on postoperative days two and seven where the observed mean low-density lipid levels were lower in Group AA compared with Groups PA and PP.

Drug safety was assessed by laboratory measures of muscle breakdown (i.e., creatine kinase) and hepatic injury (i.e., alanine aminotransferase, lactate dehydrogenase, alkaline phosphatase). There were no clinically important differences in laboratory values reflecting muscle or hepatic injury between the groups (not shown).

\section{Discussion}

In the STAR VaS trial, we used three groups to compare atorvastatin $80 \mathrm{mg}$ once daily with placebo in statin naïve 
Table 1 Baseline demographic and clinical characteristics

\begin{tabular}{|c|c|c|c|}
\hline & Group AA $(n=26)$ & Group PA $(n=16)$ & Group PP $(n=17)$ \\
\hline \multicolumn{4}{|l|}{ Demographic characteristics } \\
\hline Age (yr) Mean (SD) & $71(10)$ & $67(11)$ & $69(11)$ \\
\hline Female Sex & $4(15.4 \%)$ & $4(25.0 \%)$ & $3(17.7 \%)$ \\
\hline Smoker & $20(76.9 \%)$ & $10(62.5 \%)$ & $14(82.4 \%)$ \\
\hline \multicolumn{4}{|l|}{ Comorbidities } \\
\hline Hypertension & $12(46.2 \%)$ & $12(75.0 \%)$ & $12(70.6 \%)$ \\
\hline Cerebral Vascular Disease & $1(3.9 \%)$ & $3(18.8 \%)$ & $4(23.5 \%)$ \\
\hline Hypercholesterolemia & $3(11.5 \%)$ & $1(6.3 \%)$ & $2(11.8 \%)$ \\
\hline Peripheral Vascular Disease & $12(46.2 \%)$ & $8(50 \%)$ & $10(58.8 \%)$ \\
\hline Coronary Artery Disease & $12(46.2 \%)$ & $3(18.8 \%)$ & $4(23.5 \%)$ \\
\hline Congestive Heart Failure & $1(3.9 \%)$ & $0(0 \%)$ & $1(5.9 \%)$ \\
\hline Obstructive Lung Disease & $3(11.5 \%)$ & $3(18.8 \%)$ & $3(17.7 \%)$ \\
\hline Atrial Fibrillation & $4(15.4 \%)$ & $1(6.3 \%)$ & $3(17.7 \%)$ \\
\hline \multicolumn{4}{|l|}{ Drugs } \\
\hline Angiotension Drug & $7(26.9 \%)$ & $7(43.8 \%)$ & $5(29.4 \%)$ \\
\hline Nitrates & $1(3.9 \%)$ & $0(0 \%)$ & $1(5.9 \%)$ \\
\hline Calcium Channel Blocker & $4(15.4 \%)$ & $2(12.5 \%)$ & $5(29.4 \%)$ \\
\hline Beta Blocker & $9(34.6 \%)$ & $8(50 \%)$ & $2(11.8 \%)$ \\
\hline Diuretic & $11(42.31 \%)$ & $7(43.8 \%)$ & $8(47.1 \%)$ \\
\hline Acetylsalicylic acid & $9(34.6 \%)$ & $9(56.3 \%)$ & $6(35.3 \%)$ \\
\hline Clopidogrel & $0(0 \%)$ & $2(12.5 \%)$ & $1(5.9 \%)$ \\
\hline NSAID & $0(0 \%)$ & $4(25 \%)$ & $1(5.9 \%)$ \\
\hline COX-2 Inhibitor & $4(15.4 \%)$ & $2(12.5 \%)$ & $1(5.9 \%)$ \\
\hline Fenofibrate Drug & $1(3.9 \%)$ & $1(6.3 \%)$ & $2(11.8 \%)$ \\
\hline \multicolumn{4}{|l|}{ Procedure } \\
\hline Aortic Surgery & $9(34.6 \%)$ & $5(31.3 \%)$ & $5(29.4 \%)$ \\
\hline Infrainguinal Revascularization & $7(26.9 \%)$ & $8(50.0 \%)$ & $9(52.9 \%)$ \\
\hline Nonvascular Surgery & $10(38.5 \%)$ & $3(18.8 \%)$ & $3(17.7 \%)$ \\
\hline \multicolumn{4}{|l|}{ Primary and Secondary outcomes } \\
\hline Baseline CRP: Median [Q1, Q3] & $4.7[1.8,8.0]$ & $3.9[2.7,12.2]$ & $4.5[2.3,9.2]$ \\
\hline Baseline LDL: Median [Q1, Q3] & $2.6[2.1,3.3]$ & $3.2[2.6,3.8]$ & $2.7[2.2,3.5]$ \\
\hline Baseline HDL: Median [Q1, Q3] & $1.1[1.0,1.4]$ & $1.0[0.9,1.2]$ & $1.2[1.1,1.7]$ \\
\hline Baseline Triglycerides: Median [Q1, Q3] & $1.5[1.1,2.3]$ & $1.7[1.2,2.0]$ & $1.5[1.1,1.8]$ \\
\hline Baseline Total Cholesterol: Median [Q1, Q3] & $4.7[4.3,5.5]$ & $5.1[4.6,5.6]$ & $4.7[4.2,5.3]$ \\
\hline
\end{tabular}

NSAID $=$ nonsteroidal anti-inflammatory drug. COX $=$ cyclooxygenase inhibitor. CRP $=$ C-reactive protein and levels are $\mathrm{mg} \cdot \mathrm{L}^{-1}$. $\mathrm{LDL}=$ low density lipoprotein cholesterol; HDL = high density lipoprotein cholesterol; all lipid, triglycerides, and cholesterol measures are $\mathrm{mmol} \cdot \mathrm{L}^{-1}$

patients who had, or at were risk for, atherosclerotic disease and who underwent noncardiac surgery. Our goal was to determine if the recommendations encouraging perioperative statin therapy, as advocated by the European Society of Cardiology, ${ }^{12}$ were applicable to patients presenting a week or less before surgery.

Atorvastatin was started seven days preoperatively or on the day of surgery, and in both cases, it was continued for seven postoperative days. We found that atorvastatin, regardless of duration of treatment, did not reduce perioperative inflammation as measured by CRP levels at $48 \mathrm{hr}$ postoperatively. The hypothesized beneficial CRP reduction of $33 \%$ from use of atorvastatin was not achieved. The relatively wide confidence intervals around the differences in CRP are a reflection of our sample size of 60 participants as well as the large variability among patients in the observed CRP measurements. Nevertheless, our data do not support the hypothesized CRP reductions of $33 \%$. We did find that atorvastatin reduced serum lipid levels when it was initiated seven days preoperatively and to a lesser extent if started on the day of surgery, thus suggesting the drug was having some effect on our participants. We did not encounter differences 


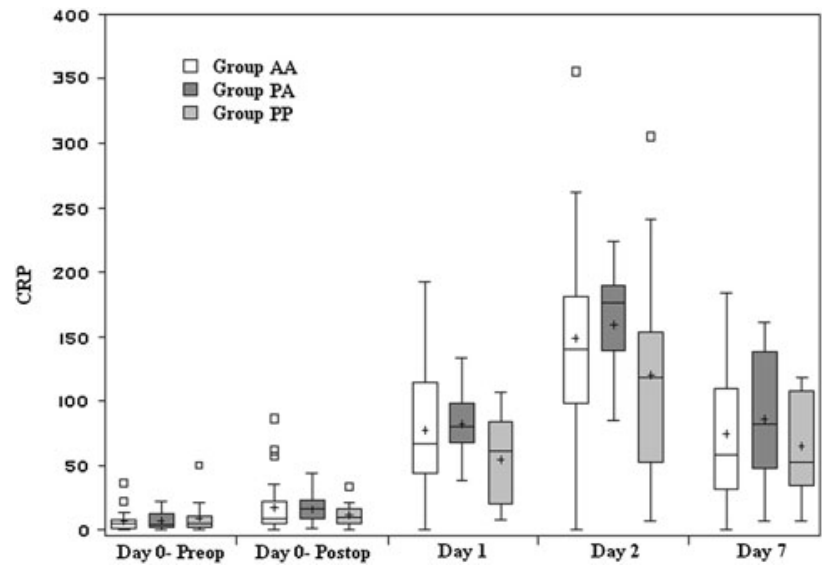

Fig. 2 Mean C-reactive protein levels. C-reactive protein levels are $\mathrm{mg} \cdot \mathrm{L}^{-1}$

in drug tolerance or evidence of harmful effects as measured by laboratory levels of muscle and liver injury. In our study, atorvastatin did not appear to reduce cardiac complications as measured by serum troponin levels, ECG, and $48 \mathrm{hr}$ of Holter monitoring. Our trial is limited, however, in that it was designed and powered to evaluate perioperative differences in CRP rather than clinical outcomes including cardiac complications.

The recommendations from the European Society of Cardiology, ${ }^{12}$ which advocate starting perioperative statin a minimum of one week before surgery in patients at increased perioperative cardiac risk, do not appear to be feasible based on our present clinical practice. Our inability to recruit patients with seven days remaining before surgery required us to modify our study recruitment. To enhance recruitment, we modified our randomization schedule to include a short randomization arm in Groups PA and PP. In an attempt to ensure a balance in groups, we preferentially directed patients presenting more than seven days ahead of surgery to Group AA. As a result, there were more subjects in Group AA than in either Group PA or Group PP. Despite this, allocation concealment and blinding was maintained in all groups. However, the recruitment challenges in our study do question the feasibility and applicability of the European recommendations in practices such as ours.

Whether or not improvements are made to the timing of referrals before elective surgery, important questions will remain. Indeed, a question clinicians commonly face is whether to start a statin in a high cardiac risk statin-naive

Table 2 Analyses of CRP (mg. $\left.\mathrm{L}^{-1}\right)$

\begin{tabular}{|c|c|c|c|}
\hline & Group AA $(n=26)$ & Group PA $(n=16)$ & Group PP $(n=17)$ \\
\hline CRP at baseline Mean, (SD) & $7.0(7.9)$ & $7.0(6.4)$ & $8.8(12.1)$ \\
\hline CRP at $48 \mathrm{hr}$ Mean, (SD) & $148.5(76.3)$ & $159.7(44.5)$ & $120.1(83.1)$ \\
\hline Change in CRP (48 hr - baseline) Mean, (SD) & $141.0(72.4)$ & $153.5(42.2)$ & $111.2(84.6)$ \\
\hline \multirow[t]{2}{*}{ Adjusted means at $48 \mathrm{hr}$ from ANCOVA analysis* } & 148.8 & 167.7 & 125.7 \\
\hline & AA $v s$ PA & AA $v s$ PP & PA vs PP \\
\hline Adjusted mean differences $(95 \% \mathrm{CI})$ from ANCOVA & $-18.9(-76.9$ & $23.0(-29.7$ to 75.8$)$ & $42.0(-17.3$ to 101.2$)$ \\
\hline $\begin{array}{l}\text { Adjusted mean differences }(95 \% \mathrm{CI}) \\
\text { from regression analysis that included potential c }\end{array}$ & $-20.1(-81.2$ & $22.7(-31.7$ to 77.2$)$ & $42.8(-20.0$ to 105.7$)$ \\
\hline
\end{tabular}

*Analysis included type of procedure and baseline CRP as covariates. All pairwise confidence intervals are adjusted for multiplicity using Tukey's method. **Analysis included type of procedure, baseline CRP, presence of CAD at baseline, and use of one of acetylsalicylic acid, COX-2 Inhibitor, NSAIDS as covariates. All pairwise confidence intervals are adjusted for multiplicity using Tukey's method. CRP $=$ C-reactive protein; $\mathrm{CI}=$ confidence interval; $\mathrm{ANCOVA}=$ analysis of covariance; $\mathrm{CAD}=$ coronary artery disease; $\mathrm{COX}=$ cyclooxygenase inhibitor; NSAIDs $=$ nonsteroidal anti-inflammatory drugs

Table 3 Myocardial complications

\begin{tabular}{|c|c|c|c|c|c|c|c|c|}
\hline & \multicolumn{2}{|l|}{ Injury } & \multirow[t]{2}{*}{ Holter Not Performed } & \multicolumn{2}{|l|}{ Ischemia } & \multicolumn{2}{|c|}{ New Arrhythmia Detected } & \multirow[t]{2}{*}{ Total } \\
\hline & Troponin Elevation & Infarction Criteria & & No & Yes & None & Any & \\
\hline Group AA & $4(15 \%)$ & $2(8 \%)$ & $5(19 \%)$ & $18(86 \%)$ & $3(14 \%)$ & $11(52 \%)$ & $10(48 \%)$ & 26 \\
\hline Group PA & $2(13 \%)$ & $1(6 \%)$ & $1(6 \%)$ & $12(80 \%)$ & $3(20 \%)$ & $8(53 \%)$ & $7(47 \%)$ & 16 \\
\hline Group PP & $3(18 \%)$ & $1(6 \%)$ & $2(12 \%)$ & $13(87 \%)$ & $2(13 \%)$ & $9(60 \%)$ & $6(60 \%)$ & 17 \\
\hline Total & $9(15 \%)$ & $4(7 \%)$ & $8(14 \%)$ & $43(84 \%)$ & $8(16 \%)$ & $28(55 \%)$ & $23(45 \%)$ & 59 \\
\hline
\end{tabular}

Holter not performed because of the presence of chronic atrial fibrillation $(n=6)$ and withdrawal from the study $(n=2)$. See text for definition of myocardial ischemia as detected by Holter monitoring 

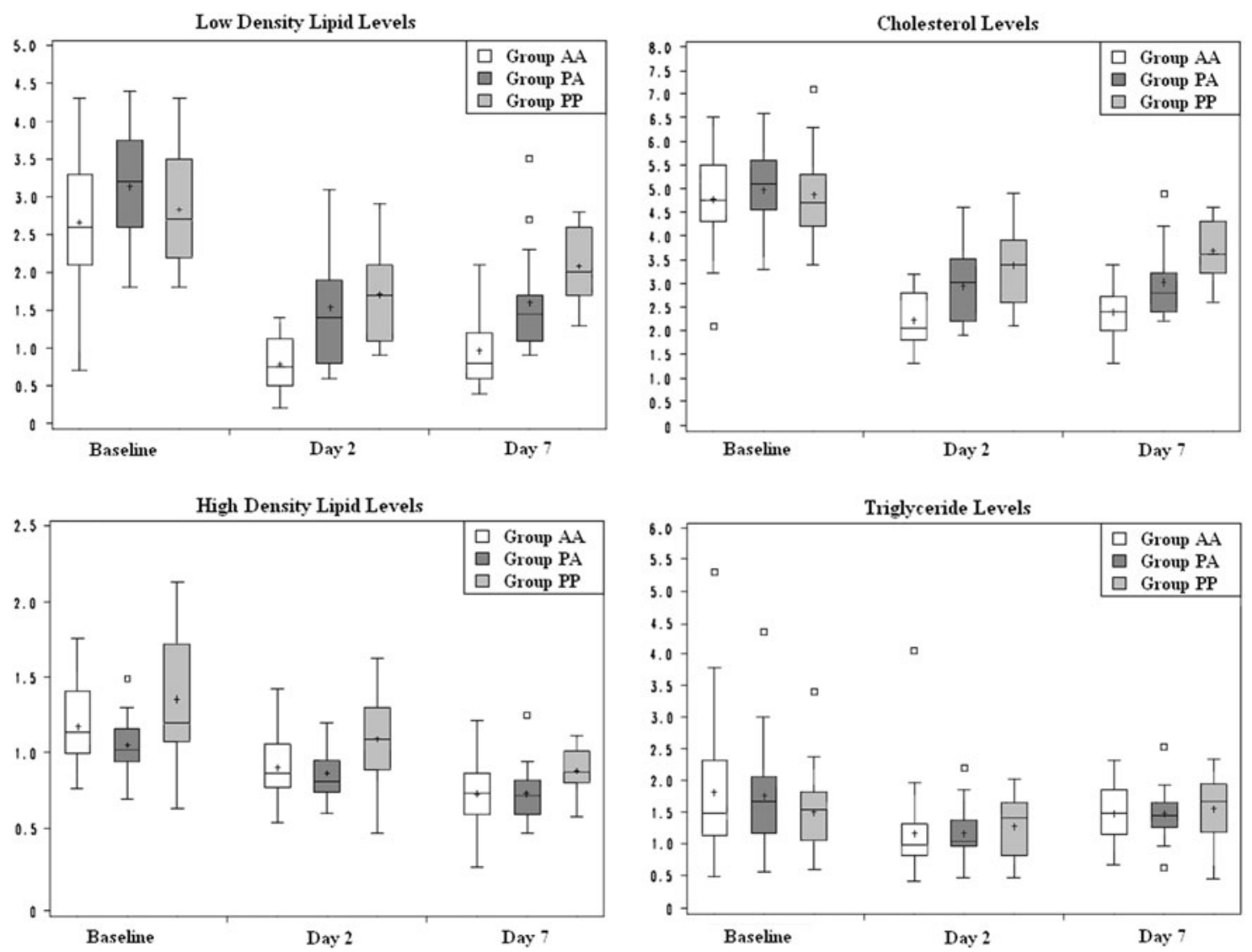

Fig. 3 Lipid changes. All levels are in $\mathrm{mmol} \cdot \mathrm{L}^{-1}$

patient who requires emergency or urgent noncardiac surgery. Our findings that there is no decrease in inflammation with acute administration of statin therapy differs from three other randomized trials. The DECREASE III study randomly assigned 497 statin naive patients undergoing vascular surgery to receive fluvastatin or placebo for a median of 37 days before surgery and a minimum of 30 days after surgery. ${ }^{13}$ Fluvastatin reduced a composite outcome of death from cardiovascular causes or myocardial infarction from $10.1 \%$ in the placebo group to $4.8 \%$ in the fluvastatin group (hazard ratio, $0.47 ; 95 \%$ confidence interval, 0.24 to $0.94 ; P=0.03$ ). Schouten reported a $21 \%$ relative reduction in CRP levels preoperatively but did not report CRP levels following surgery. Further evidence comes from the DECREASE IV trial ${ }^{14}$ in which fluvastatin $80 \mathrm{mg}$ administered a median of 34 days before surgery and 30 days after surgery reduced the primary outcome of cardiac death and myocardial infarction 30 days after surgery compared with control, although not significantly $(3.2 \%$ vs $4.9 \%$, respectively; $P=0.17) .{ }^{16}$ This was a $2 \times 2$ trial conducted in 1,066 noncardiac surgical patients considered to be at intermediate risk for cardiac complications. The trial included a bisoprolol titration arm (starting at $2.5 \mathrm{mg}$ ) and fluvastatin (80 $\mathrm{mg}$ fixed dose) with drugs being started at a median of 34 days before surgery. Durazzo et al. compared a 45-day perioperative course of atorvastatin $20 \mathrm{mg}$ started a mean of 30 days before surgery with placebo in 100 patients undergoing vascular surgery. ${ }^{18}$ Using a composite end point of cardiac death, myocardial infarction, unstable angina, or cerebral vascular accident, Durazzo showed significantly fewer events at six months following surgery in the patients randomized to atorvastatin $20 \mathrm{mg}$ than in those with placebo ( $8 \%$ vs $26 \%$, respectively; $P=0.031$ ).

The most important difference between these trials and our trial is the duration of statin therapy before surgery. In our study, the administration of atorvastatin for seven days or less before surgery was not associated with a beneficial reduction in CRP. Another difference between the DECREASE studies and our study was the choice of statin, i.e., fluvastatin $v s$ atorvastatin. It would seem unlikely that atorvastatin would be ineffective as it has proven particularly effective for improving inflammatory levels, including CRP, ${ }^{15,19}$ and it has been shown to be superior to other statins after acute coronary events in the nonoperative setting. ${ }^{15}$ Atorvastatin was also used with benefit in the trial of Durazzo et al. ${ }^{18}$ While the dose of atorvastatin in STAR VaS was larger than that chosen by Durazzo, our higher dose is associated with rapid onset and benefit in 
nonoperative myocardial infarction studies. ${ }^{15,19}$ Feringa et al. reported that higher statin doses correlated with lower perioperative and late cardiac complications in patients undergoing major vascular surgery. ${ }^{20}$ Thus, if the findings of the DECREASE trials and the Durazzo trial are combined, the results suggest that statin therapy of 30 days or more is necessary to achieve benefit.

The European Society of Cardiology Clinical Practice Guidelines recommend that statins be started in high-risk surgery patients, optimally from 30 days to at least one week before surgery (Class Ib). ${ }^{12}$ Our three-group design evaluated the onset of both anti-inflammatory and lipid lowering effects of atorvastatin in surgical patients. The design attempts to simulate two relatively common scenarios of how high-risk surgical patients present for surgery: 1) surgery within one week; and 2) emergency surgery or no preoperative assessment. Regardless of the situation, the absorption of a statin drug in the postoperative period is a concern in all perioperative statin trials. However, the beneficial changes in lipid levels evident in those administered a statin, even on the day of surgery, would suggest that the drug was absorbed and effective. The lack of benefit for reducing postoperative inflammation as measured by CRP suggests that a longer preoperative duration of drug therapy may be required. Therefore, results from trials where statins were administered for a minimum of thirty days should not be extrapolated to the acute administration of statins. Indeed, our study found no evidence of reductions in inflammation, myocardial ischemia, or arrhythmia associated with a course of high-dose statin treatment lasting seven days or less. Although we cannot absolutely discount the possibility that imbalances in our groups could have contributed to our results, at present time, there is insufficient evidence to support the initiation of statin treatment as a risk reduction strategy for urgent or emergent surgery. Also, the routine initiation of statin in high-risk noncardiac surgical patients presenting for surgery in seven days or less cannot be supported until further studies are performed. The minimum duration of statin therapy before surgery to reap benefit remains unknown. If benefit relies on statins' antiinflammatory properties, our results suggest that more than seven days of therapy are required. To achieve optimal statin benefit, preoperative evaluation and preparation should precede elective surgery by up to a month.

Rather than designing a trial to evaluate a clinical outcome, such as cardiac morbidity or mortality, we designed and powered our trial to evaluate perioperative differences in CRP associated with atorvastatin therapy. Some random baseline differences were apparent between the groups, and attempts were made to balance them, including baseline coronary artery disease and use of medication (Table 1). Adjusted and unadjusted results were similar, however, and differences in CRP levels were not significantly affected. A definitive statin trial to determine if statin reduces perioperative cardiac complications would realistically require well over 4,000 patients (assuming a 10\% event rate, a 25\% relative risk reduction and a power of 0.8 ). C-reactive protein was therefore selected as it reflects a proposed mechanism of benefit, and elevations of CRP are predictive of perioperative complications. ${ }^{20,21}$ Acute use of statins have been shown to modify CRP levels in the nonoperative setting. ${ }^{17,19}$ The MIRACL study showed that starting atorvastatin $80 \mathrm{mg} 24-96 \mathrm{hr}$ after an acute coronary event reduced cardiac ischemic complications and reduced CRP levels. ${ }^{17,21}$ C-reactive protein itself may not be simply a marker of inflammation, but it may contribute directly to vascular inflammation and plaque destabilization. ${ }^{17}$ Elevated CRP levels are associated with cardiac complications where even an elevation of $1 \mathrm{mg} \cdot \mathrm{L}^{-1}$ was associated with a significantly increased risk of stroke, myocardial infarction, and cardiac death. ${ }^{22,23}$ Our study results did not answer whether or not short term atorvastatin therapy may benefit other inflammatory mediators, including interleukins, in the perioperative setting.

In conclusion, we compared two atorvastatin groups with placebo for high cardiac risk participants undergoing surgery. Patients started on atorvastatin seven days preoperatively or immediately before surgery showed no beneficial changes in plasma CRP levels following surgery.

Acknowledgements The authors gratefully acknowledge the skills of Ms. Denise Wozny, Ms. Sharon Finlay, and the Methods Centre; the effort of the Department of Anesthesiology's Research Team; and the cooperation of our surgical colleagues. A special thanks to Drs. Howard Nathan and Jean Yves Dupuis for their insightful reviews of the manuscript.

Disclosure The authors declare no commercial or non-commercial affiliations that are or may be perceived to be a conflict of interest with the work. The Methods Centre, Ottawa Hospital Research Institute managed and analyzed the data under the supervision of the study investigators. None of the funding sources had a role in the trial design, conduct, data collection, analyses, data interpretation, or writing of this manuscript. The sponsors were not involved in developing the analysis plan or in the analysis. The corresponding author had full access to all data in the trial. The investigators had final responsibility for the decision to submit for publication.

Funding The STARVaS trial was funded by grants from the Heart and Stroke Foundation of Ontario and The Canadian Anesthesiologists' Society. The research team was supported by the Chair's Research Fund, Department of Anesthesiology, University of Ottawa. Drs. Neilipovitz and Bryson were supported by the Ottawa Hospital Anesthesia Alternate Funds Association. 


\section{Appendix 1: Detail entry criteria}

All patients undergoing noncardiac surgery are eligible if they:

1. are $\geq 45 \mathrm{yr}$ of age

2. fulfill any one of the following six criteria:

a. history of coronary artery disease as defined by any of the following six criteria:

i. history of angina

ii. prior myocardial infarction

iii. prior positive exercise stress test

iv. prior documentation of cardiac ischemia on nuclear stress testing

v. prior coronary artery arteriographic evidence of atherosclerotic stenosis $>50 \%$ of vessel diameter

vi. ECG with pathological $Q$ waves in two contiguous leads

b. peripheral vascular disease as defined by any one of the following three criteria:

i. intermittent claudication (i.e., leg pain on walking that disappears in $<10$ minutes on standing) that is known or likely to be due to atherosclerotic disease

ii. an ankle/arm systolic blood pressure ratio $\leq$ 0.90 in either leg at rest

iii. angiographic or Doppler study demonstrating $>70 \%$ stenosis

c. history of stroke (i.e., focal neurological deficit that persisted for at least 1 week after onset) thought due to atherothrombotic disease (i.e., NOT a lacunar stroke, hemorrhagic stroke, or embolic stroke secondary to atrial fibrillation)

d. hospitalization for congestive heart failure within 3 years of randomization

e. undergoing major vascular surgery (i.e., vascular surgery excluding arteriovenous shunts for dialysis, vein stripping procedures, and carotid endarterectomies); OR

f. any three of the following six risk factors

i. high-risk type of surgery (i.e., intrathoracic or intraperitoneal)

ii. any history of congestive heart failure

iii. diabetes and currently on oral hypoglycemic agents or insulin therapy

iv. preoperative serum creatinine $>175 \mu \mathrm{mol} \cdot \mathrm{L}^{-1}$

v. age $>70 \mathrm{yr}$

vi. history of transient ischemic attack (TIA), i.e., a transient focal neurological deficit that lasted $<24$ hours
Appendix 2: Perioperative investigations

\begin{tabular}{|c|c|c|c|c|c|c|}
\hline Test & $\begin{array}{c}\text { Day 7 } \\
\text { (preoperative } \\
\text { 7 or more days) }\end{array}$ & $\begin{array}{c}\text { Day 0 } \\
\text { (immediate } \\
\text { preoperative) }\end{array}$ & $\begin{array}{c}\text { Day 0 } \\
(8 \mathrm{hr} \\
\text { postoperative) }\end{array}$ & Day 1 & $\begin{array}{c}\text { Day 7 } \\
\mathbf{2}\end{array}$ & $\begin{array}{c}\text { Day } \\
\text { (discharge day if } \\
\text { earlier) }\end{array}$ \\
\hline ECG & $\mathrm{X}$ & & $\mathrm{X}$ & $\mathrm{X}$ & $\mathrm{X}$ & $\mathrm{X}$ \\
\hline ALT & $\mathrm{X}$ & $\mathrm{X}$ & & & $\mathrm{X}$ & $\mathrm{X}$ \\
\hline LDH & $\mathrm{X}$ & $\mathrm{X}$ & & & $\mathrm{X}$ & $\mathrm{X}$ \\
\hline ALP & $\mathrm{X}$ & $\mathrm{X}$ & & & $\mathrm{X}$ & $\mathrm{X}$ \\
\hline CK & $\mathrm{X}$ & $\mathrm{X}$ & & $\mathrm{X}$ & $\mathrm{X}$ & $\mathrm{X}$ \\
\hline Trop & $\mathrm{X}$ & & $\mathrm{X}$ & $\mathrm{X}$ & $\mathrm{X}$ & $\mathrm{X}$ \\
\hline CRP & $\mathrm{X}$ & $\mathrm{X}$ & $\mathrm{X}$ & $\mathrm{X}$ & $\mathrm{X}$ & $\mathrm{X}$ \\
\hline LDL & $\mathrm{X}$ & $\mathrm{X}$ & & & $\mathrm{X}$ & $\mathrm{X}$ \\
\hline HDL & $\mathrm{X}$ & $\mathrm{X}$ & & & $\mathrm{X}$ & $\mathrm{X}$ \\
\hline CHOL & $\mathrm{X}$ & $\mathrm{X}$ & & & $\mathrm{X}$ & $\mathrm{X}$ \\
\hline TG & $\mathrm{X}$ & $\mathrm{X}$ & & & $\mathrm{X}$ & $\mathrm{X}$ \\
\hline Holter & \multicolumn{2}{|r|}{} \\
\hline
\end{tabular}

$\mathrm{ECG}=$ electrocardiogram; ALT $=$ alanine aminotransferase; $\mathrm{LDH}=$ lactate dehydrogenase; ALP = alkaline phosphatase; $\mathrm{CK}=$ creatine kinase; Trop $=$ troponin; $\mathrm{CRP}=$ high sensitivity $\mathrm{C}$-reactive protein; $\mathrm{LDL}=$ low density lipoprotein cholesterol; HDL $=$ high density lipoprotein cholesterol; $\mathrm{CHOL}=$ total cholesterol; $\mathrm{TG}=$ triglycerides; Holter monitoring is continuous monitoring for $48 \mathrm{hr}$; shaded areas are non-test times

\section{References}

1. Boushra NN, Muntazar M. Review article: The role of statins in reducing perioperative cardiac risk: physiologic and clinical perspectives. Can J Anesth 2006; 53: 1126-47.

2. Fleischmann KE, Goldman L, Young B, Lee TH. Association between cardiac and noncardiac complications in patients undergoing noncardiac surgery: outcomes and effects on length of stay. Am J Med 2003; 115: 515-20.

3. Landesberg $G$. The pathophysiology of perioperative myocardial infarction: facts and perspectives. J Cardiothorac Vasc Anesth 2003; 17: 90-100.

4. Dawood MM, Gutpa DK, Southern J, Walia A, Atkinson JB, Eagle KA. Pathology of fatal perioperative myocardial infarction: implications regarding pathophysiology and prevention. Int $\mathbf{J}$ Cardiol 1996; 57: 37-44.

5. Cohen MC, Aretz TH. Histological analysis of coronary artery lesions in fatal postoperative myocardial infarction. Cardiovasc Pathol 1999; 8: 133-9.

6. Ellis $S G$, Hertzer NR, Young JR, Brener S. Angiographic correlates of cardiac death and myocardial infarction complicating major nonthoracic vascular surgery. Am J Cardiol 1996; 77: 1126-8.

7. Hogue CW Jr, Stamos T, Winters KJ, Moulton M, Krucylak PE, Cooper $J D$. Acute myocardial infarction during lung volume reduction surgery. Anesth Analg 1999; 88: 332-4.

8. Mangano DT, Hollenberg $M$, Fegert $G$, et al. Perioperative myocardial ischemia in patients undergoing noncardiac surgeryI: incidence and severity during the 4 day perioperative period. The Study of Perioperative Ischemia (SPI) Research Group. J Am Coll Cardiol 1991; 17: 843-50.

9. Herroeder $S$, Durieux ME, Hollmann MW. Inflammatory responses after surgery. Hosp Med 2002; 63: 99-103.

10. Devereaux PJ, Yang H, Yusuf S, et al. Effects of extended-release metoprolol succinate in patients undergoing non-cardiac surgery (POISE trial): a randomised controlled trial. Lancet 2008; 371: 1839-47. 
11. Takeda T, Hoshida S, Nishino M, Tanouchi J, Otsu K, Hori M. Relationship between effects of statins, aspirin and angiotensin II modulators on high-sensitive C-reactive protein levels. Atherosclerosis 2003; 169: 155-8.

12. Poldermans D, Bax JJ, Boersma E, et al. Guidelines for preoperative cardiac risk assessment and perioperative cardiac management in non-cardiac surgery: the Task Force for Preoperative Cardiac Risk Assessment and Perioperative Cardiac Management in Non-cardiac Surgery of the European Society of Cardiology (ESC) and endorsed by the European Society of Anaesthesiology (ESA). Eur J Anaesthesiol 2010; 27: 92-137.

13. Schouten O, Boersma E, Hoeks SE, et al. Fluvastatin and perioperative events in patients undergoing vascular surgery. N Engl J Med 2009; 361: 980-9.

14. Dunkelgrun M, Boersma E, Schouten O, et al. Bisoprolol and fluvastatin for the reduction of perioperative cardiac mortality and myocardial infarction in intermediate-risk patients undergoing noncardiovascular surgery: a randomized controlled trial (DECREASE-IV). Ann Surg 2009; 249: 921-6.

15. Sever PS, Dahlof B, Poulter NR, et al. Prevention of coronary and stroke events with atorvastatin in hypertensive patients who have average or lower-than-average cholesterol concentrations, in the Anglo-Scandinavian Cardiac Outcomes Trial-Lipid Lowering Arm (ASCOT-LLA): a multicentre randomised controlled trial. Lancet 2003; 361: 1149-58.

16. Schulz KF, Altman DG, Moher D, CONSORT Group. CONSORT 2010 statement: updated guidelines for reporting parallel group randomized trials. Ann Intern Med 2010; 2010(152): 726-32.
17. Kinlay $S, S c h w a r t z G G$, Olsson AG, et al. High-dose atorvastatin enhances the decline in inflammatory markers in patients with acute coronary syndromes in the MIRACL study. Circulation 2003; 108: 1560-6.

18. Durazzo AE, Machado FS, Ikeoka DT, et al. Reduction in cardiovascular events after vascular surgery with atorvastatin: a randomized trial. J Vasc Surg 2004; 39: 967-75.

19. Correia LC, Sposito AC, Lima JC, et al. Anti-inflammatory effect of atorvastatin $(80 \mathrm{mg})$ in unstable angina pectoris and non-Qwave acute myocardial infarction. Am J Cardiol 2003; 92: 298-301.

20. Feringa HH, Schouten $O$, Karagiannis SE, et al. Intensity of statin therapy in relation to myocardial ischemia, troponin $\mathrm{T}$ release, and clinical cardiac outcome in patients undergoing major vascular surgery. J Am Coll Cardiol 2007; 50: 1649-56.

21. Schwartz GG, Olsson AG, Ezekowitz MD, et al. Effects of atorvastatin on early recurrent ischemic events in acute coronary syndromes: the MIRACL study: a randomized controlled trial. JAMA 2001; 285: 1711-8.

22. Ridker PM, Rifai N, Rose L, Buring JE, Cook NR. Comparison of C-reactive protein and low-density lipoprotein cholesterol levels in the prediction of first cardiovascular events. N Engl J Med 2002; 347: 1557-65.

23. Sabatine MS, Morrow DA, Jablonski KA, et al. Prognostic significance of the Centers for Disease Control/American Heart Association high-sensitivity C-reactive protein cut points for cardiovascular and other outcomes in patients with stable coronary artery disease. Circulation 2007; 115: 1528-36. 